\title{
Juliano Cerci, Stefano Fanti, Dominique Delbeke (Eds): Oncological PET/CT with Histological Confirmation
}

\author{
Springer International Publishing, 2016, (ISBN 978-3-319-27878-0 )
}

\author{
Valentina Piscopo $^{1} \cdot$ Luigi Mansi $^{1}$
}

Published online: 24 January 2017

(C) Springer-Verlag Berlin Heidelberg 2017

This is a little, less than one hundred pages, original book supporting the role of PET/CT in optimizing biopsy procedures. The authors are well-known international experts: Juliano Cerci, working at the PET/CT Center in Curitiba, Brazil; Stefano Fanti, from the University of Bologna, Italy; and Dominique Delbeke, from Vanderbilt University in Nashville, USA.

PET/CT-guided biopsy offers a new diagnostic approach, which may be important in many patients such as those with a single highly concentrating lesion, in those with a diffuse disease, as a suspicious lymphoma, in which it is important to individuate the more favorable site of biopsy, in patients in which there is no clear information on the exclusive basis of morphological examinations, in patients with multiple metastases and an occult primary, and in patients which manifest a suspicious relapse after a prolonged period of remission.

Structured in eight chapters, the publication is further divided into subchapters, all including clinical cases and color images. The first three chapters briefly describe the hybrid imaging history in guiding biopsy, the procedural technique and contraindications, including also any acute complications that may occur during the biopsy. The remaining chapters describe clinical applications of PET/CT-guided biopsy, mainly using ${ }^{18} \mathrm{~F}-\mathrm{FDG}$, but also considering the possible role of other radiocompounds, such as ${ }^{11} \mathrm{C}$-choline and ${ }^{18} \mathrm{~F}$-FLT. More specifically, the fourth chapter is based on the use of ${ }^{18}$ F-FDG, dedicated to lymphoma, which describes the biopsy procedure performed under PET/CT guidance, specific clinical indications and the role that this method may present in confirming or in supporting a histological re-evaluation of a suspicious lesion. The fifth chapter describes the diagnostic procedure in patients with prostate cancer using ${ }^{11} \mathrm{C}$-choline as per the experience of the University of Bologna. The sixth chapter proposes the use of ${ }^{18} \mathrm{~F}-\mathrm{FLT}$, tracing growing rate, as a surrogate marker of cancer not showing uptake in inflammation/infection, and, therefore, being more reliable with respect to ${ }^{18} \mathrm{~F}-\mathrm{FDG}$ in patients in which a high rate of false positive results is expected. The seventh chapter describes the procedure and the utility of PET/CT-guided biopsy in patients with suspected pancreatic lesions, and the eighth chapter presents the application of the procedure in skeletal and soft tissue lesions.

The interest of this agile publication is in supporting $\mathrm{PET} / \mathrm{CT}$ as a guide to a better practice in biopsy. Being the only uptake present in viable tissue, this approach may be particularly useful in cases with complex lesions including necrosis and/or fibrosis, or in patients with multiple lesions, when a relapse is suspicious. In this sense, we suggest this book not only to nuclear physicians and radiologists involved in biopsy, but also to surgeons and oncologists interested in better understanding the possibilities of this new strategy.
Luigi Mansi

luigi.mansi@unina2.it

1 Università della Campania "Luigi Vanvitelli”, Caserta, Italy 